\title{
SATELLITE-DERIVED AIR POLLUTANTS AND THEIR CORRELATIONS WITH URBAN FORM IN GUANGDONG, CHINA
}

\author{
Lili $\mathrm{Li}^{1}$, Xidan Feng ${ }^{1}$, Tao. Chen ${ }^{2} *$ \\ ${ }^{1}$ College of Environmental Science and Engineering, Zhongkai University of Agricultural and Engineering, Guangzhou 510225, P R \\ China - sanlygis@163.com, fengxidan@aliyun.com \\ ${ }^{2}$ The Environmental Research Institute; MOE Key Laboratory of Theoretical Chemistry of Environment, South China Normal \\ University, Guangzhou 510006, P R China - tao.chen@m.scnu.edu.cn
}

Commission III, WG III/8

KEY WORDS: $\mathrm{PM}_{2.5}, \mathrm{NO}_{2}$, Urban Form, Landscape Metrics, Guangdong Province

\begin{abstract}
:
The ways cities grow and evolve spatially are crucial factors which affect urban aerosol pollution. Understanding the spatial distribution of air pollutants and their correlations with urban form is of great significance to the improvement of urban atmospheric environment and regional sustainable development of urbanization. In this study, we firstly examined the spatial variations of satellite-derived $\mathrm{PM}_{2.5}$ and $\mathrm{NO}_{2}$ and urban form metrics in Guangdong, and also explored their relationships. The results indicated that the highest and lowest values of $\mathrm{PM}_{2.5}$ and $\mathrm{NO}_{2}$ mainly occur over the Pearl River Delta (PRD) region, and over the eastern Guangdong, respectively. For the size and shape of urban patches, urban form had significant effects on air pollutants in Guangdong. $\mathrm{PM}_{2.5}$ was positively correlated with AREA_AM, CA and SHAPE_AM, and $\mathrm{NO}_{2}$ was positively correlated with LPI, PLAND and AREA_AM, while both of them were negatively related to PARA_AM and ENN_AM. It is inferred that polycentric urban form was associated with low $\mathrm{PM}_{2.5}$ and $\mathrm{NO}_{2}$ concentration, and reasonable urban planning would help mitigate the fine particle pollution.
\end{abstract}

\section{INTRODUCTION}

Urban development is manifested by the spatial expansion of urban land use and the evolution of ecological patterns driven by human economic development (Yan and Huang, 2013). Urban form, which reflects the spatial distribution of population, buildings, traffic roads and infrastructure, affects how the city functions, how much energy it consumes and how much air pollutants it produces (EPA, 2001; Ewing et al., 2003; Borrego et al., 2006).

Urban form can affect air quality by influencing configurations of streets, population density, distribution of emission sources and local meteorology including urban heat island effects the energy efficiency of buildings (Weng, 2003; Ewing and Rong, 2008; Zhou and Levy, 2008; Bereitschaft and Debbage, 2013). Pollutant dispersion around buildings is associated to the packing density of buildings, as well as building-height variability (Tominaga and Stathopoulos, 2013; Blocken, 2014), and the interaction of atmospheric conditions with buildings creates complex air flow structures in urban street canyons (Yazid et al., 2014; Lateb et al., 2016). Therefore, the spatial expansion and evolution of urban is a key factor affecting regional air quality (Clark et al., 2011; Han et al., 2015; Lu and Liu, 2016). Reasonable urban forms can reduce traffic congestion, save energy, and mitigate the negative impacts of aerosol emissions on regional healthy development. An indepth understanding of urban form and its relationship with atmospheric aerosols helps to identify efficient urban land use patterns and develop healthy cities.
Located in the southernmost part of China, Guangdong experiences unprecedented rapid economic growth and population explosion in the past three decades, and its urbanization rate has increased from $66.2 \%$ in 2010 to $69.2 \%$ in 2016. Land cover changes rapidly, manifested as urban expansion, farmland loss and deforestation, resulting in more refined urban land use patterns, higher landscape fragmentation and stronger landscape heterogeneity. Due to rapid industrial development and huge energy consumption during urbanization process, air pollutant emissions have increased sharply and air quality in the province has deteriorated, greatly impairing the health of the population and the visibility over the region, have drawn widespread attention from the government and the public. The objectives of this paper are 1) to examine the spatial variation of air pollutants $\left(\mathrm{PM}_{2.5}\right.$ and $\left.\mathrm{NO}_{2}\right)$ and urban form in Guangdong during 2016, and 2) to explore the correlations between air pollutants and urban form, aiming to provide a better understanding of $\mathrm{PM}_{2.5}, \mathrm{NO}_{2}$ and urban form in Guangdong as an empirical case.

\section{DATA AND METHOD}

The annual $\mathrm{PM}_{2.5}$ products is downloaded from http://beta.sedac.ciesin.columbia.edu/data/set/sdei-globalannual-gwr-pm2-5-modis-misr-seawifs-aod, which consist of annual concentrations $(\mu \mathrm{g} / \mathrm{m} 3)$ of ground-level fine particulate matter $\left(\mathrm{PM}_{2.5}\right)$ with a spatial resolution of $0.1^{\circ}$, combining AOD retrievals from multiple satellite instruments including the NASA Moderate Resolution Imaging Spectroradiometer (MODIS), Multi-angle Imaging SpectroRadiometer (MISR),

\footnotetext{
* Corresponding author
} 
and the Sea-Viewing Wide Field-of-View Sensor (SeaWiFS) (Van et al., 2016, 2018).

Data on the tropospheric $\mathrm{NO}_{2}$ column concentration were collected from Royal Netherlands Meteorological Institute (KNMI) DOMINO v2.0 products, which are available at http://www.temis.nl/airpollution/no2col/no2month_tropomi.php. For this data, the spatial resolution was $0.125 \times 0.125^{\circ}$ latitudelongitude (equivalent to $12.5 \mathrm{~km} \times 12.5 \mathrm{~km}$ ), and the temporal resolution was 1 month. The OMI $\mathrm{NO}_{2}$ product is a postprocessing data set, based on the most complete set of OMI orbits, improved level-1b radiance data, analysed meteorological fields, and actual spacecraft data., which make it superior to the near-real time $\mathrm{NO}_{2}$ data for scientific studies (Boersma et al., 2011).

Land cover data used in our study was $500 \mathrm{~m}$-resolution MODIS LUCC product (MCD12Q1) with IGBP classification scheme identifying 17 land cover classes (Friedl et al., 2010), and the accuracy is estimated to be $73.6 \%$ globally. The spatial distribution of urban elements has been mainly considered with nine landscape metrics, including Total Urban Area (CA), Percentage of Urban (PLAND), Largest Patch Index (LPI), Area-weighted mean patch area (AREA_AM), Area-weighted shape index (SHAPE_AM), Area-weighted Mean Perimeterarea ratio (PARA_MN), Area-weighted Mean Euclidean Nearest Neighbor Distance (ENN_MN), Patch Cohesion Index (COHESION) and Aggregation Index (AI). These metrics were calculated to characterize the urban form of 21 cities in Guangdong, with FRAGSTATS 4.2. After the KolmogorovSmirnov normal distribution test is performed on the dataset from 21 cities, the Pearson coefficient was calculated by bivariate correlation analysis to explore the correlation of air pollutants and urban metrics by Data Analysis Software SPSS 22.0 .

\section{RESULTS AND DISCUSSION}

\subsection{Spatial Variation Of $\mathrm{PM}_{2.5}$ And $\mathrm{NO}_{2}$ In Guangdong}

The geographical distribution of ground-level annual average $\mathrm{PM}_{2.5}$ over the Guangdong province in 2016 is shown in Figure 1. The annual $\mathrm{PM}_{2.5}$ ranged from 14 to 38 , with an average value of $25 \mu \mathrm{g} / \mathrm{m}^{3}$ in Guangdong, below the national standard for annual average $\mathrm{PM}_{2.5}\left(35 \mu \mathrm{g} / \mathrm{m}^{3}\right)$. The highest values of $\mathrm{PM}_{2.5}\left(>25 \mu \mathrm{g} / \mathrm{m}^{3}\right)$ mainly occur over the Pearl River Delta (PRD) region, whereas the lowest values $\left(<15 \mu \mathrm{g} / \mathrm{m}^{3}\right)$ mainly occur over the eastern Guangdong. The maximum $\mathrm{PM}_{2.5}$ occurs in Foshan, Zhongshan, Guangzhou and Dongguan, which is mainly attributed to large emissions from industrial pollution, urban traffic, and secondary aerosol generated by strong photochemical reactions. The minimum $\mathrm{PM}_{2.5}$ mainly located in Chaozhou, Jieyang, Shantou and Shanwei, where the industry was less developed than PRD.

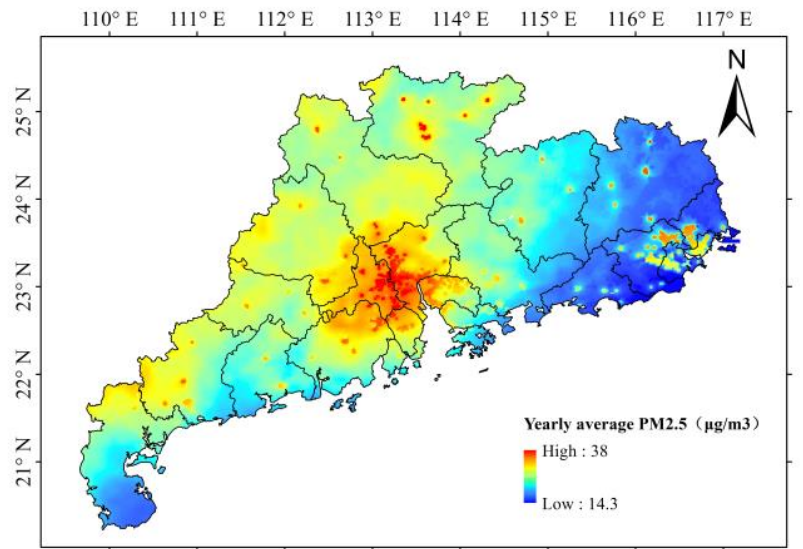

Figure 1. The spatial distribution of yearly average $\mathrm{PM}_{2.5}$ in Guangdong, 2016

The spatial distribution of annual average $\mathrm{NO}_{2}$ column concentration over the Guangdong province in 2016 is shown in Figure 2, which is quite different from the spatial characteristics of $\mathrm{PM}_{2.5}$. The highest values of $\mathrm{NO}_{2}$ mainly occur over the middle Pearl River Delta (PRD) region, including Guangzhou, Dongguan, Foshan, Zhenshen and Zhongshan. Cities along the boundary of PRD showed relatively higher $\mathrm{NO}_{2}$ concentrations, whereas cities outside PRD had low $\mathrm{NO}_{2}$ values.

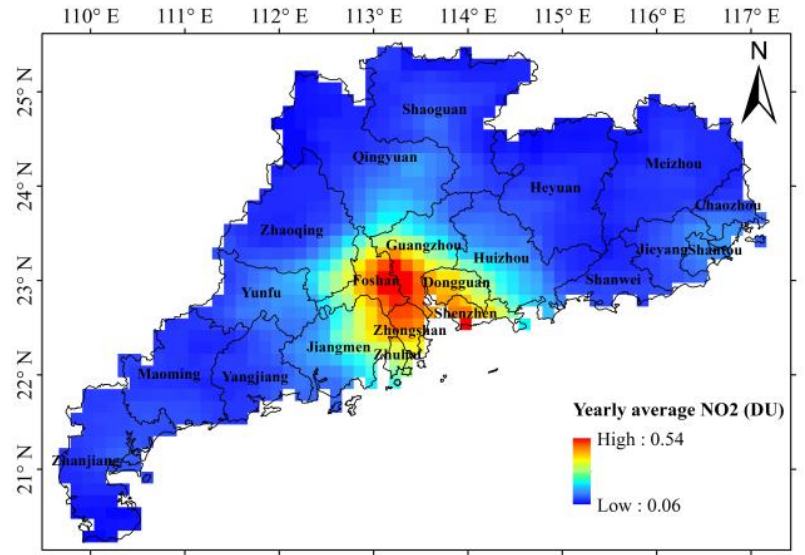

Figure 2. The spatial distribution of yearly average $\mathrm{NO}_{2}$ in Guangdong, 2016

\subsection{Urban Landscape Characteristics Of Cities In Guangdong}

Nine urban landscape metrics in 21 cities were calculated by FRAGSTATS 4.2. For these metrics, CA is an important measurement to represent the expansion of urban land use, PLAND quantifies the proportional abundance of urban land in the landscape, and LPI characterizes the percentage of total landscape area comprised by the largest patch, AREA_AM is the area-weighted mean area of urban patches, SHAPE_AM measures the complexity of patch shape compared to a standard shape (square) of the same size, PARA_AM describes urban landscape configuration in terms of the complexity of patch shape, ENN_AM is interpreted as the main measurement of spatial connection between the urban patches, COHESION measures the physical connectedness of urban patches, and AI shows the like adjacencies of patches for urban land use. 
The configurations of urban form for 21 cities in Guangdong varied significantly (Figure 3). All the data were standardized so that the ranges were between 0-1. Dongguan had the maximum of PLAND, LPI, COHESION and AI, and the minimum values of PARA_AM and ENN_AM. The minimum of CA and AREA_AM appeared in Foshan, and the minimum of these two metrics occurred in Yangjiang and Shanwei, respectively. Dramatic variations of the metrics in these cities suggested a diversity of urban form in Guangdong, showing a rhomboid, rhombus or constellation form.
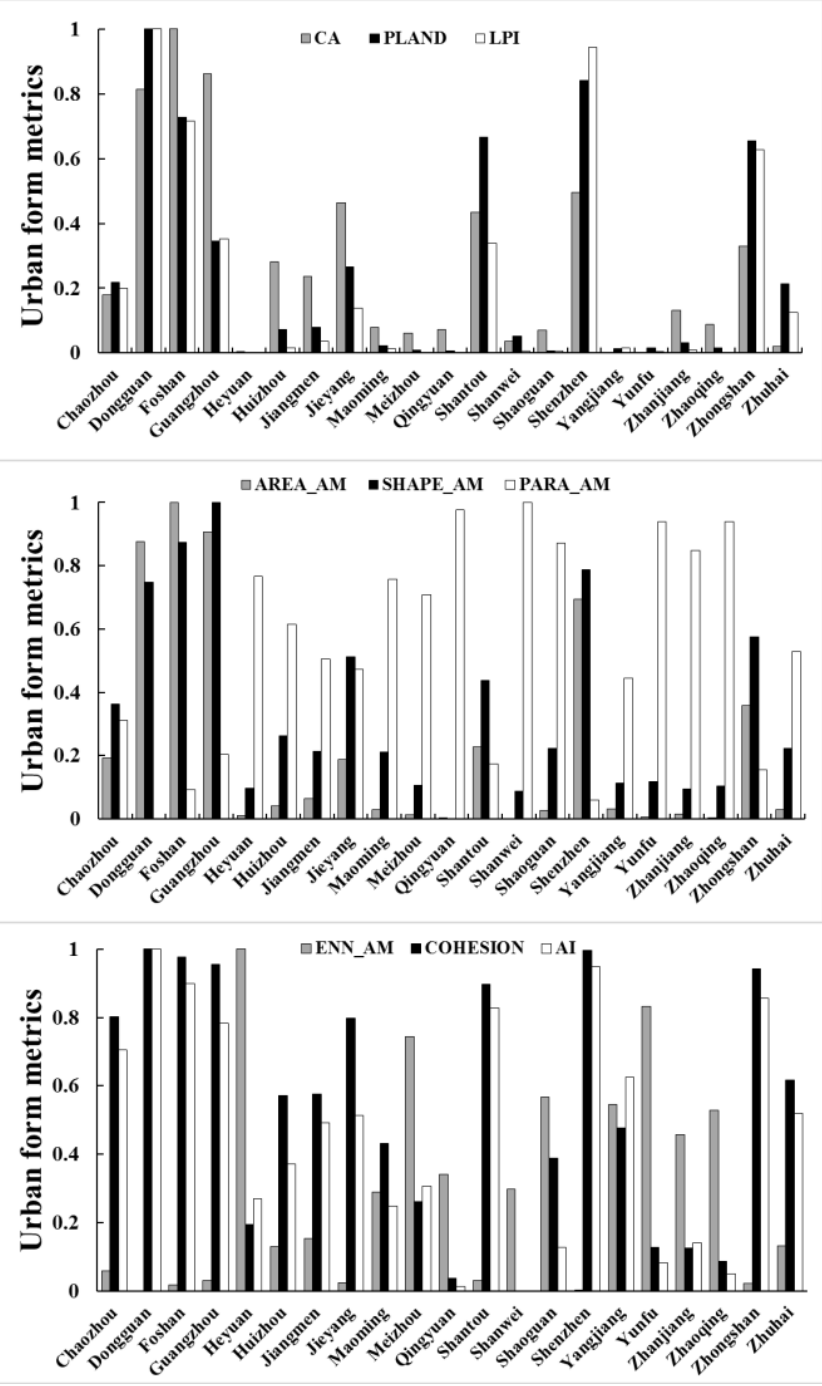

Figure 3. Nine urban form metrics of 21 cities in Guangdong, 2016

\subsection{Relationship Between Air Pollutants And Urban Landscape In Guangdong}

Table 1 shows the relationships of $\mathrm{PM}_{2.5}, \mathrm{NO}_{2}$ and urban form metrics, respectively. AREA_AM, CA and SHAPE_AM had the most significant impacts on the distribution of $\mathrm{PM}_{2.5}$, while LPI, PLAND and AREA_AM played the most significant impacts in the distribution of $\mathrm{NO}_{2}$, with the correlation coefficient being $0.862,0.821$ and 0.785 . Due to the fast economic development in Guangdong, the urbanization process accelerated rapidly in Guangdong and the total urban areas were tremendously enlarged. The larger the city appeared, the more energy was consumed. Meanwhile, the wide distribution of various urban patches led to a large amount of air pollutant emissions. In theory, according to the relationships between $\mathrm{PM}_{2.5}, \mathrm{NO}_{2}$ and urban landscape pattern, the problem of $\mathrm{PM}_{2.5}$ and $\mathrm{NO}_{2}$ could be dealt with by changing the percentage of specific patches, but it would be difficult to decrease construction land area in quickly developing cities. So urban landscape configuration is of great significance to regional air pollution.

Moreover, $\mathrm{PM}_{2.5}$ and $\mathrm{NO}_{2}$ were negatively related to PARA_AM and ENN_AM. The Pearson coefficients of $\mathrm{NO}_{2}$ and PARA_AM, ENN_AM were -0.765 and -0.62 at the significance level of $\mathrm{P}=0.01$, implying the closely negative relationship between $\mathrm{NO}_{2}$ and urban patch configuration. Therefore, important facilities should be constructed in the subcentres of the city to decrease travelling distances between different urban patches. It could be inferred that the polycentric urban form reduces commuting distance and leads to less vehicle pollution, posing a positive impact on urban air quality (Loo and Chow, 2011).

\begin{tabular}{|c|c|c|}
\hline & $\mathbf{P M}_{2.5}$ & NO $_{2}$ \\
\hline CA & $0.488^{*}$ & $0.696^{* *}$ \\
\hline PLAND & 0.345 & $0.821^{* *}$ \\
\hline LPI & 0.421 & $0.862^{* *}$ \\
\hline AREA_AM & $0.542^{*}$ & $0.785^{* *}$ \\
\hline SHAPE_AM & $0.449^{*}$ & $0.774^{*}$ \\
\hline PARA_AM & -0.276 & $-0.765^{* *}$ \\
\hline ENN_AM & -0.187 & $-0.62^{* *}$ \\
\hline COHESION & 0.279 & $0.734^{* *}$ \\
\hline AI & 0.263 & $0.757^{* *}$ \\
\hline
\end{tabular}

** Significance at the 0.01 level.

* Significance at the 0.05 level.

Table 1. The Pearson coefficient (r) between urban form metrics and air pollutants

\section{CONCLUSION}

Rapid Urbanization and economic development have resulted in dramatic increase in energy consumption, and consequently a large amount of pollutant emissions. This study tries to investigate the implication for reasonable urban form to alleviate environmental problems. In this paper, we explored satellite-derived $\mathrm{PM}_{2.5}$ and $\mathrm{NO}_{2}$ variations and their relationships with to urban form in Guangdong province based on satellite data of $\mathrm{PM}_{2.5}$ concentration and land use map. Urban form was characterized using nine spatial metrics, including size, shape, regularity and fragmentation of urban patches. Results showed that the spatial patterns of $\mathrm{PM}_{2.5}$ and $\mathrm{NO}_{2}$ vary among the cities and the maximum values mainly occurs in the developed Pearl River Delta. The relationships between air pollutants and urban form metrics inferred that the spatial distributions of $\mathrm{PM}_{2.5}$ and $\mathrm{NO}_{2}$ were closely related to the size, shape and fragmentation of urban patches, suggested that optimizing urban form could improve regional air quality. 


\section{ACKNOWLEDGEMENTS}

Guangdong NSF (2017A030310D05) and State Key Laboratory of Organic Geochemistry Program (SKLOGA201603A) are acknowledged for financial supports. We thank the NASA Earth System for the $\mathrm{PM}_{2.5}$ and LUCC products. We also acknowledge the free use of tropospheric $\mathrm{NO}_{2}$ column data from the OMI sensor from www.temis.nl.

\section{REFERENCES}

Bereitschaft, B., and Debbage, K., 2013. Urban form, air pollution, and $\mathrm{CO} 2$ emissions in large U.S. metropolitan areas. The Professional Geographer, 65 (4), 612-635.

Blocken, B., 2014. 50 years of computational wind engineering: past, present and future. Journal of Wind Engineering and Industrial Aerodynamics, 129, 69-102.

Boersma, K. F., Eskes, H. J., Dirksen, R. J., Van der A, R. J., Veefkind, J. P., Stammes, P., Huijnen, V., Kleipool, Q. L., Sneep, M., Claas, J., Leitao, J., Richter, A., Zhou, Y., Brunner, D., 2011. An improved tropospheric $\mathrm{NO}_{2}$ column retrieval algorithm for the Ozone Monitoring Instrument. Atmos. Meas. Tech., 4, 1905-1928.

Borrego, C., Martins, H., Tchepel, O., Salmim, L., Monteiro, A. Miranda, A. I., 2006. How urban structure can affect city sustainability from an air quality perspective. Environmental Modelling and Software, 21(4), 461-467.

Clark, L. P., Millet, D. B., Marshall, J. D., 2011. Air quality and urban form in U.S. urban areas: Evidence from regulatory monitors. Environmental Science and Technology, 45, 70287035 .

Environmental Protection Agency (EPA), 2001. Our built and natural environments: A technical review of the interactions between land use, transportation and environmental quality. Environmental Protection Agency, Washington, DC., USA.

Ewing, R., Pendall, R., Chen, D., 2003. Measuring sprawl and its transportation impacts. Transportation Research Record: Journal of the Transportation Research Record, 1831, 175-183.

Ewing, R., and Rong, F., 2008. The impact of urban form on U.S. residential energy use. Housing Policy Debate, 19 (1), 130 .

Friedl, M. A., Sulla-Menashe, D., Tan, B., Schneider, A., Ramankutty, N., Sibley, A., Huang, X., 2010. MODIS Collection 5 global land cover: Algorithm refinements and characterization of new datasets. Remote Sensing of Environment, 114, 168-182.

Han, L., Zhou, W., Li, W., 2015. City as a major source area of fine particulate $\left(\mathrm{PM}_{2.5}\right)$ in China. Environmental Pollution, 206, 183-187.
Lateb, M., Meroney, R.N., Yataghene, M., Fellouah, H., Saleh, F., Boufadel, M.C., 2016. On the use of numerical modelling for near-field pollutant dispersion in urban environments: A review. Environmental Pollution, 208, 271-283.

Loo, B.P.Y., and Chow, A.S.Y., 2011. Spatial restructuring to facilitate shorter commuting: an example of the relocation of Hong Kong International Airport. Urban Study, 48(8), 16811694.

Lu, C., and Liu, Y., 2016. Effects of China's urban form on urban air quality. Urban Study, 53(12), 2607-2623.

Tominaga, Y., and Stathopoulos, T., 2013. CFD simulation of near-field pollutant dispersion in the urban environment: a review of current modeling techniques. Atmospheric Environment, 79, 716-730.

Van Donkelaar, A., Martin, R. V., Brauer, M., Hsu, N. C., Kahn, R. A., Levy, R. C., Lyapustin, A., Sayer, A. M., Winker, D. M., 2016. Global Estimates of Fine Particulate Matter Using a Combined Geophysical-Statistical Method with Information from Satellites. Environmental Science \& Technology, 50 (7), 3762-3772.

Van Donkelaar, A., Martin, R. V., Brauer, M., Hsu, N. C., Kahn, R. A., Levy, R. C., Lyapustin, A., Sayer, A. M., Winker, D. M., 2018. Global Annual PM2.5 Grids from MODIS, MISR and SeaWiFS Aerosol Optical Depth (AOD) with GWR, 1998-2016. Palisades, NY: NASA Socioeconomic Data and Applications Center (SEDAC).

Weng, Q. H., 2003. Fractal analysis of satellite-detected urban heat island effect. Photogrammetric Engineering \& Remote Sensing, 69 (5), 555-566.

Yan, M., and Huang, J.C., 2013. Review on the research of urban spatial expansion. Progress in Geography, 32(7), 10391050 .

Yazid, A.W. M., Sidik, N. A. C., Salim, S. M., Saqr, K. M., 2014. A review on the flow structure and pollutant dispersion in urban street canyons for urban planning strategies. Simulation, 90(8), 892-916.

Zhou, Y., and Levy, J. I., 2008. The impact of urban street canyons on population exposure to traffic-related primary pollutants. Atmospheric Environment, 42(13), 3087-3098. 